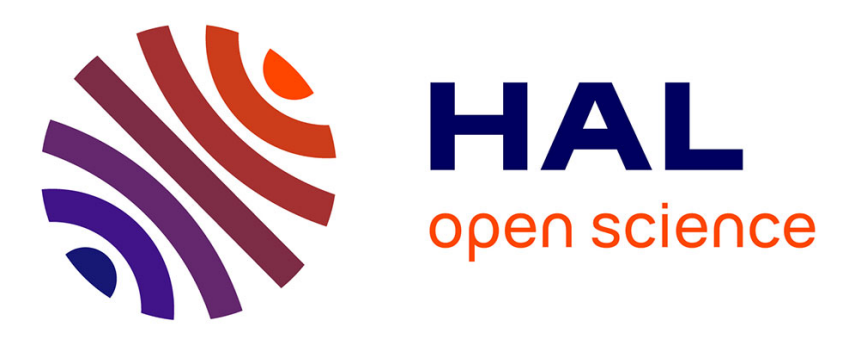

\title{
Pollination services provided by wild insects to kiwifruit (Actinidia deliciosa)
}

\author{
Marcos Miñarro, Kent W. Twizell
}

\section{To cite this version:}

Marcos Miñarro, Kent W. Twizell. Pollination services provided by wild insects to kiwifruit (Actinidia deliciosa). Apidologie, 2015, 46 (3), pp.276-285. 10.1007/s13592-014-0321-2 . hal-01284446

\section{HAL Id: hal-01284446 \\ https://hal.science/hal-01284446}

Submitted on 7 Mar 2016

HAL is a multi-disciplinary open access archive for the deposit and dissemination of scientific research documents, whether they are published or not. The documents may come from teaching and research institutions in France or abroad, or from public or private research centers.
L'archive ouverte pluridisciplinaire HAL, est destinée au dépôt et à la diffusion de documents scientifiques de niveau recherche, publiés ou non, émanant des établissements d'enseignement et de recherche français ou étrangers, des laboratoires publics ou privés. 


\title{
Pollination services provided by wild insects to kiwifruit (Actinidia deliciosa)
}

\author{
Marcos MiñarRo, Kent W. Twizell \\ Servicio Regional de Investigación y Desarrollo Agroalimentario (SERIDA), Apdo. 13, 33300, Villaviciosa, Asturias, \\ Spain
}

Received 13 June 2014 - Revised 21 August 2014 - Accepted 22 September 2014

\begin{abstract}
Managed bees are used to transfer pollen from male to female flowers in kiwifruit, but the contribution of wild insects has been long overlooked. We approached such contribution with multiple criteria (pollinator abundance, foraging behavior, pollinating efficiency, and response to weather conditions) in the absence of imported colonies. An abundant and rich community of pollinators (57\% were non-Apis insects) visited kiwifruit flowers and assured a fruit set and size not different from those obtained by optimal hand pollination. Honeybees were more abundant and visited more flowers per time but bumblebees were more efficient on a per-visit basis. Other taxa are expected to contribute less because of their lower numbers (hoverflies, wild bees, butterflies, beetles) or their passive behavior (non-syrphid flies). Visitation patterns of pollinators were complementary. Our results highlight the important contribution of wild insects to the pollination of kiwifruit.
\end{abstract}

activity patterns / foraging behavior / pollination efficiency / pollinator complementarity / weather effect

\section{INTRODUCTION}

Kiwifruit is one of 13 leading global food crops for which entomophilous pollination is essential (Klein et al. 2007). Kiwifruit is dioecious, and insects are needed to transfer pollen from male to female vines because wind pollination is insufficient for a successful kiwifruit yield (Donovan and Read 1990; Costa et al. 1993; Vaissiere et al. 1996; González et al. 1998; Howpage et al. 2001; Pomeroy and Fisher 2002). Insects are needed not only for fruit set but also to obtain commercial fruit size because kiwifruit size is strongly correlated with seed number (Costa et al. 1993; González et al. 1998; Pomeroy and Fisher 2002), which depends on the number of pollen grains reaching the ovules. Therefore, the efficiency of

Corresponding author: M. Miñarro, mminarro@serida.org

Manuscript editor: Stan Schneider pollinating insects is important to the quantity and quality of kiwifruit production.

Several studies have demonstrated the effectiveness of using managed honeybees (Apis mellifera) (Vaissiere et al. 1996; Howpage et al. 2001, but see Clinch 1984; Costa et al. 1993) and bumblebees (Bombus spp.) (Pomeroy and Fisher 2002) to pollinate kiwifruit, yet reliance on a single species for pollination is an inherently risky strategy. Diseases, invasive predators, colony losses, or competition from non-crop food sources can threaten a pollinator species and, in turn, the pollination services they provide (Pomeroy and Fisher 2002; vanEngelsdorp et al. 2009; Fürst et al. 2014; Monceau et al. 2014). In the case of Bombus, two additional concerns should be taken into account. Firstly, the importation of non-native commercial bumblebees could competitively displace native subspecies because commercial colonies may have higher reproductive success and foraging ability than native ones, as observed in Bombus terrestris (Ings et al. 2006). Secondly, commercial bumblebee colonies can carry 
microbial parasites which are infectious and pose a significant risk not only to bumblebees but also to other pollinators (Graystock et al. 2013).

Wild bees and other native insects pollinate many crops, although their role has been mostly overlooked until recently, as a growing number of studies provide evidence of their contribution to crop pollination. Thus, recent studies have shown the positive relationship between the diversity of pollinator communities and the quantity and quality of the pollination service they provide (Brittain et al. 2013; Garibaldi et al. 2013; Rader et al. 2013a, b). Flower visitation by wild pollinators enhances fruit set independently of honeybee abundance (Garibaldi et al. 2013), and thus integrated management strategies for simultaneously taking advantage of managed pollinators and the wild bee community are recommended to increase crop yields.

Most studies of kiwifruit pollination by insects have been conducted in orchards with introduced hives of honeybees or bumblebees to measure the ability of those insects to pollinate this crop (Clinch 1984; Read et al. 1989; Donovan and Read 1990; Testolin et al. 1991; Costa et al. 1993; Vaissiere et al. 1996; González et al. 1998; Howpage et al. 2001; Pomeroy and Fisher 2002). The wild pollinator community in those studies was either not described (Read et al. 1989; Donovan and Read 1990; González et al. 1998; Pomeroy and Fisher 2002) or was negligible compared with the managed bee species (Clinch 1984; Testolin et al. 1991; Costa et al. 1993; Vaissiere et al. 1996; Howpage et al. 2001). A recent study conducted in India, however, described a rich insect community visiting kiwifruit flowers with half of the foragers being other than Apis or Bombus insects (Sharma et al. 2013).

We aimed to assess the contribution of native, wild insects to kiwifruit pollination using multiple criteria (Rogers et al. 2013). Pollinators might vary in abundance over time and space (Rader et al. 2013a), their response to weather conditions (Vicens and Bosch 2000b; Brittain et al. 2013) or their foraging behavior and pollination efficiency (Vicens and Bosch 2000a; Rader et al. 2013a, b). An integrative approach is thus needed to attribute pollination services and predict how differences in a bee community or foraging environment will affect those services (Bartomeus et al. 2013; Rader et al. 2013a, b; Rogers et al. 2013). We assessed pollinator abundance, foraging behavior, pollinating efficiency, and activity patterns in relation to weather conditions in an experimental kiwifruit orchard not supplemented with bee colonies.

\section{MATERIAL AND METHODS}

\subsection{Site description}

The experiments were carried out in June during the kiwifruit flowering period in an experimental orchard of our research station, located at Villaviciosa (Asturias), on the north coast of Spain ( $43^{\circ} 28^{\prime} 24^{\prime \prime} \mathrm{N}, 5^{\circ} 26^{\prime} 48^{\prime \prime} \mathrm{W}$; $6 \mathrm{~m}$ a.s.l). Asturias has a temperate oceanic climate with rainfall usually exceeding $1100 \mathrm{~mm}$ fairly evenly spread out over the year. The orchard, $1000 \mathrm{~m}^{2}$ in size, was planted in 1992 for pollinator selection experiments with female vines of the kiwifruit cultivar "Hayward" and an assortment of male vines that originated as seedlings from open pollinated "Hayward" vines. Kiwifruit flowers do not produce nectar and both sexes produce pollen although female pollen is not viable. Male and female vines were mixed in a similar number without a regular arrangement. The orchard was surrounded by experimental plantations of other crops (mainly apple, but also chestnut, bean, and blueberry). None of those crops had flowers when kiwifruit was in bloom. The orchard ground cover was mechanically mowed several times, and during the sampling, no flowers were available on the ground. That is, no flower competition was expected in the orchard's immediate vicinity. No colonies of honeybees or bumblebees were introduced in this or in other crops of the research station. The orchard was neither irrigated nor treated with any pesticide. Air temperature, relative humidity, solar radiation, rainfall, and wind speed were recorded every hour by a weather station located $150 \mathrm{~m}$ away from the experimental orchard.

\subsection{Pollinator abundance}

Pollinator visitation to kiwifruit flowers was visually registered on 9 days between 13 and 26 June 2013, six times a day (at hourly intervals from 0900 to 1400 hours). At each sampling event $(n=54)$, the observer walked slowly for $10 \mathrm{~min}$ along kiwifruit rows counting 
the number of insects that visited the flowers. To avoid disrupting kiwifruit foragers, we did not collect any insects for identification. Insects were grouped as predatory hoverflies (Diptera: Syrphidae), Eristalis hoverflies (Diptera: Syrphidae), non-syrphid flies (Diptera), honeybees (Hymenoptera: Apidae), bumblebees (Hymenoptera: Apidae), wild bees (others than bumblebees) (Hymenoptera: Apoidea), ants (Hymenoptera: Formicidae), butterflies (Lepidoptera), and beetles (Coleoptera). Excepting for honeybees, we were able to identify by sight different morphospecies at each group, although they were not quantified.

\subsection{Foraging behavior}

We recorded the foraging behavior of the most abundant pollinators. Firstly, we observed the insect visits to pistillate flowers and calculated the rate of legitimate visits as the percentage of cases in which the insect contacted the stigmas, thus allowing pollen transfer (legitimate visits). Secondly, we followed foraging bouts of individual pollinators until we lost sight of them and recorded visit duration on a flower and time spent shuttling between flowers, from which we calculated the visitation rate (flowers visited per minute).

\subsection{Pollination efficiency}

We compared four pollination treatments in terms of fruit quantity (fruit set) and quality (fruit weight): "natural pollination," "single-visit pollination," "hand pollination," and "wind pollination." For the natural pollination treatment, female flowers were freely exposed to pollinators. All the other treatments involved bagged flowers to prevent insect visitation. These flowers were individually covered with polyethylene tulle bags (mesh size $1 \mathrm{~mm}$ ) for the duration of flowering. As stigmas are no longer receptive after petal falling, bags were removed immediately after petal abscission to avoid shading the developing fruits. For the single-visit pollination treatment, an open female flower was unbagged and watched continuously until an insect (honeybee or bumblebee) visited it. After the visit, the flower was bagged again. This treatment allowed comparing the pollination efficiency at taxonomic level. For the hand pollination treatment, an open female flower was unbagged to be hand pollinated by touching the stigmas with anthers of three different male flowers. Then they were bagged again. This treatment was assumed to fulfill the pollen requirements of a flower and thus allowed testing for pollen limitation in the other treatments (Holzschuh et al. 2012), that is, if an inadequate quantity of pollen was reducing reproductive success (fruit set and weight) (Ashman et al. 2004). Pollen limitation in a given treatment would occur when fruit set and/or weight was lower than in the hand pollination treatment. For the wind pollination treatment, female flowers were bagged throughout the flowering period to prevent visitation and test insect contribution to pollination. In all the treatments, fruit set was recorded 1 month after bloom and fruit was weighed 2 weeks before harvest.

\subsection{Data analyses}

Mann-Whitney $U$ tests were used to analyze differences between pollinator species in the time spent on flowers and shuttling between flowers. Chi-square tests were used to analyze differences among pollinator species in the frequency of legitimate visits. The effect of pollination treatments on fruit set was analyzed with chi-square tests; treatment effect on fruit weight was analyzed using one-way ANOVA followed by the Tukey test to establish differences among treatments. Stepwise multiple regressions were used to model insect response to weather variables. All these statistical analyses were performed with SPSS (IBM SPSS Statistics version 19.0.0).

We generated pollinator response surfaces to temperature and time of the day using Surfer 8 (Golden Software Inc.). Each response surface consisted of a twodimensional grid with time of day on the $x$-axis, temperature on the $y$-axis, and pollinator visits being analyzed as the $z$-axis (outcome variable). The response surfaces were generated through interpolation from all hour-temperature combinations recorded at each sampling event $(n=54)$ to show the expected values of visits in other conditions. Therefore, they represented the activity pattern of pollinators in response to hour and temperature not only in the observed conditions but also in hypothetical ones.

\section{RESULTS}

\subsection{Insect visits to kiwifruit flowers}

We recorded 5295 insect visits to kiwifruit flowers (Table I). Hymenopterans (76.1 \%) were the dominant order, followed by Diptera $(22.5 \%)$, 
Table I. Insects recorded visiting kiwifruit flowers.

\begin{tabular}{llllll}
\hline Order & Family & Species & Common name & Number & Percentage \\
\hline Hymenoptera & Apidae & Apis mellifera & Honeybees & 2276 & 43.0 \\
Hymenoptera & Apidae & Bombus spp. & Bumblebees & 1584 & 29.9 \\
Diptera & - & - & Flies & 644 & 12.2 \\
Diptera & Syrphidae & - & Predatory hoverflies & 291 & 5.5 \\
Diptera & Syrphidae & Eristalis spp. & & 258 & 4.9 \\
Hymenoptera & - & - & Wild bees & 109 & 2.1 \\
Hymenoptera & Formicidae & - & Ants & 62 & 1.2 \\
Lepidoptera & - & - & Butterflies & 51 & 1.0 \\
Coleoptera & - & - & Beetles & 20 & 0.4 \\
Total & & & & 5295 & 100 \\
\hline
\end{tabular}

Lepidoptera (1.0\%), and Coleoptera $(0.4 \%)$. A. mellifera and Bombus spp. were the two most frequent visitors to flowers, accounting for 43.0 and $29.9 \%$ of the total visits, respectively. Most identified Bombus belonged to the group terrestris-lucorum. Wild bees other than bumblebees (henceforth wild bees) were present in low numbers $(2.1 \%)$. Hoverflies (both Eristalis spp. and aphidophagous species) were relatively abundant (10.4\%). Non-syrphid Diptera accounted for $12.2 \%$ of the total insects.

\subsection{Activity pattern of insects and relation to weather conditions}

During the insect sampling, temperature ranged between 12.9 and $22.3{ }^{\circ} \mathrm{C}$, relative humidity between 53 and $92 \%$, rainfall between 0 and $10 \mathrm{~mm}$, radiation between 57 and $1095 \mathrm{~W} \mathrm{~m}^{-2}$, and wind speed between 0 and $2.1 \mathrm{~m} \mathrm{~s}^{-1}$. A previous analysis by Pearson's correlations showed that temperature, radiation, and humidity were highly correlated with one another $(r>0.8$ in all cases). An increase in solar radiation consequently implies an increase in air temperature and a decrease in humidity. Then, to avoid problems of multicollinearity, only one of them (temperature) was used in the multiple regression analyses. On the other hand, there was a lower correlation between wind speed and temperature $(r=0.517, P<0.001)$. Wind speed in our region is usually null or very low at the earliest hours of the day, when temperature is also lower.
Finally, temperature and rainfall were not correlated $(r=-0.245, P=0.074)$.

Stepwise multiple regressions selected temperature as the most explanatory weather variable to explain insect visits to flowers for all the insect groups (Table II). All pollinators but non-syrphid dipterans responded similarly to weather conditions by increasing abundance with temperature. The model also selected wind as an explanatory variable for non-syrphid dipterans, which were more abundantly recorded in flowers when temperature and wind were lower.

This effect may be appreciated in more detail in the pollinator response surfaces, which showed a diverse activity pattern of the different taxa to time of day and temperature (Figure 1). Non-syrphid flies showed the most different response: they were present on the flowers early in the morning regardless of the temperature, but later they were recorded mainly when temperature was below $17-18^{\circ} \mathrm{C}$ (with a few visits at the highest temperatures). Under the recorded conditions, honeybees, bumblebees, hoverflies, or wild bees were scarce early in the morning and then increased their visits to the flowers as the morning progressed and the temperature rose. However, according to the response surfaces, some differences are appreciated at a finer scale. For example, honeybee and bumblebee visits would increase with temperature regardless of the hour, being high at hypothetical high temperatures early in the morning, whereas hoverfly and wild bee visits would continue rising as the morning progressed. 
Table II. Importance of weather factors to insects visiting kiwifruit flowers as analyzed through stepwise multiple regression.

\begin{tabular}{|c|c|c|c|c|}
\hline Insect & Independent variables & $\beta$ & $P$ value & Adjusted $R^{2}$ \\
\hline \multirow[t]{2}{*}{ Honeybees } & Temperature & 0.816 & $<0.001$ & \\
\hline & Model & & & 0.659 \\
\hline \multirow[t]{2}{*}{ Bumblebees } & Temperature & 0.812 & $<0.001$ & \\
\hline & Model & & & 0.653 \\
\hline \multirow[t]{3}{*}{ Diptera } & Temperature & 0.413 & $<0.001$ & \\
\hline & Wind & -0.408 & $<0.001$ & \\
\hline & Model & & & 0.492 \\
\hline \multirow[t]{2}{*}{ Predatory hoverflies } & Temperature & 0.742 & $<0.001$ & \\
\hline & Model & & & 0.541 \\
\hline \multirow[t]{2}{*}{ Eristalis hoverflies } & Temperature & 0.632 & $<0.001$ & \\
\hline & Model & & & 0.388 \\
\hline \multirow[t]{2}{*}{ Wild bees } & Temperature & 0.653 & $<0.001$ & \\
\hline & Model & & & 0.415 \\
\hline \multirow[t]{2}{*}{ Ants } & Temperature & 0.490 & $<0.001$ & \\
\hline & Model & & & 0.226 \\
\hline \multirow[t]{2}{*}{ Butterflies } & Temperature & 0.589 & $<0.001$ & \\
\hline & Model & & & 0.334 \\
\hline \multirow[t]{2}{*}{ Beetles } & Temperature & 0.287 & 0.036 & \\
\hline & Model & & & 0.064 \\
\hline
\end{tabular}

Regarding the two most abundant foragers, bumblebees started the visits to flowers at lower temperatures than honeybees.

\subsection{Foraging behavior}

Foraging behavior was recorded for the most abundant taxa except non-syrphid flies because they were found on the flowers mainly resting. Honeybees, bumblebees, Eristalis spp., and predatory hoverflies differed in the percentage of visits in which they contacted the stigmas while feeding on pollen (i.e., legitimate visits) $\left(\chi^{2}=51.45, d . f .=\right.$ $3, P<0.001$ for the four taxa and $\chi^{2}=7.91, d . f$. $=$ $1, P<0.01$ for the comparison honeybeesbumblebees; Table III). Bumblebees showed the most efficient foraging behavior because they contacted stigmas such that pollen transfer could occur in more cases $(86.3 \%)$ than honeybees $(67.5 \%)$ and hoverflies (34-35\%). Unlike other insects, bees have a high work rate because they have to not only feed themselves but also gather sufficient resources for their offspring. Other insects (e.g., hoverflies) visit flowers only to feed themselves, and therefore it is difficult and makes little sense to assess their visit rate because after feeding on a flower, they commonly stop and rest on it or on a nearby leaf or just fly away. Therefore, visitation rates were only recorded for honeybees and bumblebees. Honeybees foraged at a single flower significantly lesser time than bumblebees $(U=7431.0, P<0.001)$, but they spent the same time shuttling between flowers $(U=6533.5$, $P=0.305$ ) (Table III). Therefore, honeybees were faster foragers on kiwifruit flowers (visited 3.6 flowers $\min ^{-1}$ ) than were bumblebees $(2.7$ flowers. $\min ^{-1}$ ).

\subsection{Pollination efficiency}

As explained above, pollination efficiency at taxonomic level was only assessed for honeybees and bumblebees. There was a significant effect of the pollination treatment on fruit set $\left(\chi^{2}=51.45\right.$, 

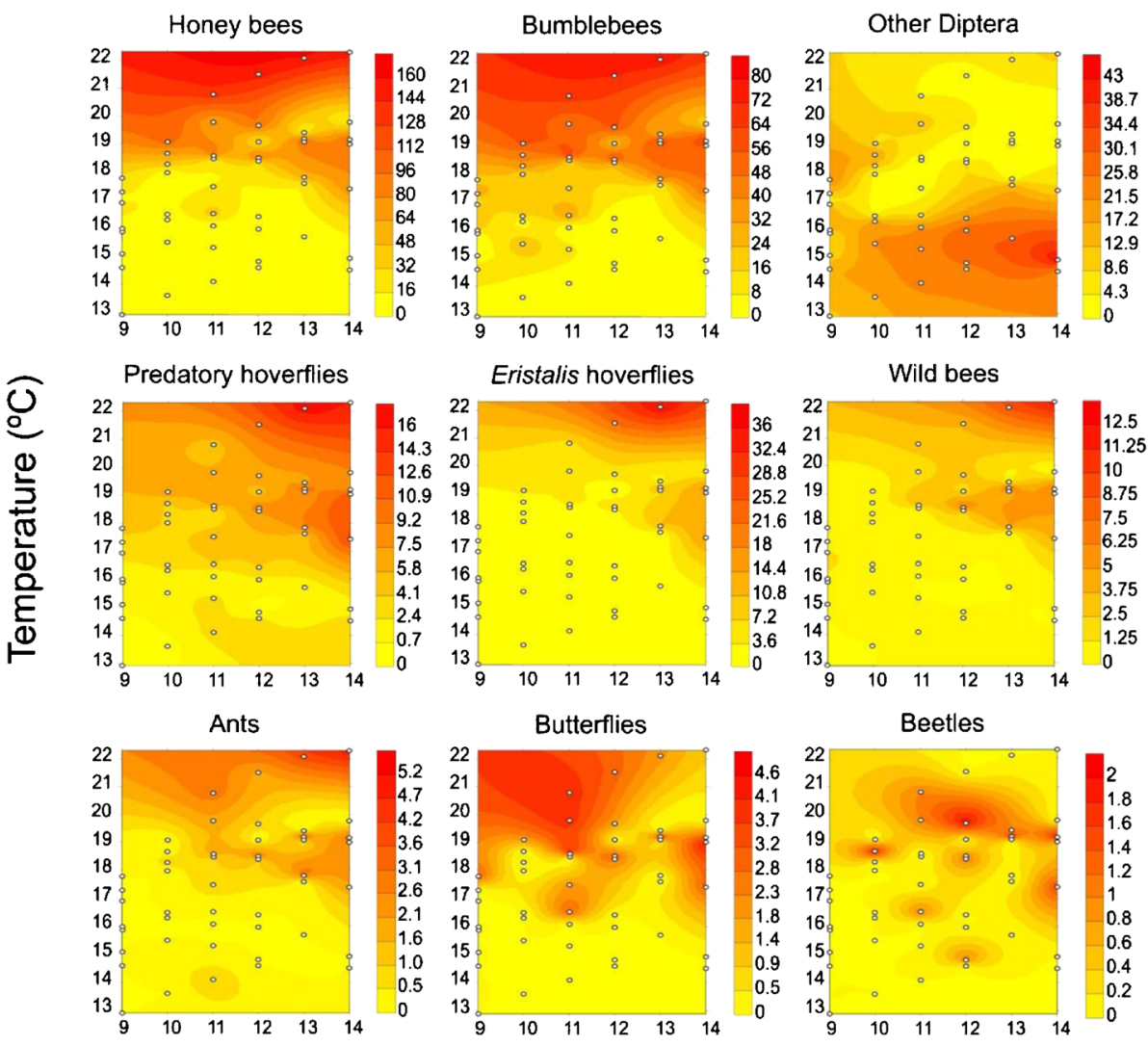

\section{Hour}

Figure 1. Response surfaces of all the insects visiting kiwifruit flowers in relation to hour and temperature. Dots indicate the combination of hour and temperature during the observation events $(n=54)$ whereas colored contours are interpolated from the number of visits in those events. The color scales represent the number of visits; note changes in scale among taxa.

d.f. $=4, P<0.001)$ and fruit weight $(F=32.37$; d.f. $=4,134 ; P<0.001$ ) (Table IV). Fruit set was over $90 \%$ in all the treatments in which insects were allowed to access the flowers (natural pollination and flowers visited once by honeybees or bumblebees) as well as in the hand pollination treatment. No significant differences on fruit set were found among those treatments $\left(\chi^{2}=3.39\right.$,

Table III. Foraging behavior of insects on kiwifruit flowers: legitimate visits (touching stigmas), visit duration on a flower, and time between flowers.

\begin{tabular}{|c|c|c|c|c|c|c|c|c|}
\hline & \multicolumn{2}{|c|}{ Legitimate visits } & \multicolumn{3}{|c|}{ Visit duration (s) } & \multicolumn{3}{|c|}{ Time between flowers (s) } \\
\hline & $N$ & $\%$ & $N$ & Mean & SE & $N$ & Mean & SE \\
\hline Apis mellifera & 80 & 67.5 & 148 & 11.85 & 0.62 & 117 & 4.62 & 0.30 \\
\hline Bombus spp. & 80 & 86.3 & 149 & 17.26 & 0.92 & 121 & 5.05 & 0.31 \\
\hline Eristalis hoverflies & 80 & 35.0 & - & - & - & - & - & - \\
\hline Predatory hoverflies & 80 & 33.8 & - & - & - & - & - & - \\
\hline
\end{tabular}


Table IV. Fruit set and fruit weight in the pollination experiments. For fruit weight, data followed by the same letter are not significantly different.

\begin{tabular}{|c|c|c|c|c|c|c|}
\hline \multirow[t]{2}{*}{ Treatment } & \multicolumn{2}{|c|}{ Fruit set } & \multicolumn{4}{|c|}{ Fruit weight (g) } \\
\hline & $N$ & $\%$ & $N$ & Mean & SE & \\
\hline \multicolumn{7}{|l|}{ Open } \\
\hline Natural pollination & 42 & 93 & 34 & 78.6 & 1.9 & a \\
\hline \multicolumn{7}{|l|}{ Bagged } \\
\hline Wind pollination & 34 & 44 & 15 & 35.8 & 4.6 & $\mathrm{c}$ \\
\hline Hand pollination & 21 & 90 & 19 & 72.3 & 2.2 & $\mathrm{a}$ \\
\hline Apis pollination & 43 & 91 & 37 & 59.4 & 2.7 & $\mathrm{~b}$ \\
\hline Bombus pollination & 35 & 100 & 34 & 79.7 & 2.7 & $\mathrm{a}$ \\
\hline
\end{tabular}

d.f. $=3, P=0.336)$. However, fruit set was only $44 \%$ in flowers to which insects could not access (wind pollination treatment) and in which pollen had to be transferred by wind. Fruit weight values resulting from single visits to flowers made by bumblebees $(79.7 \pm 2.7 \mathrm{~g}$; mean $\pm \mathrm{SE})$ were significantly higher than those of honeybees (59.4 \pm $2.7 \mathrm{~g})$ but similar to those obtained after natural $(78.6 \pm 1.9 \mathrm{~g})$ and hand $(72.3 \pm 2.2 \mathrm{~g})$ pollination. Fruit weight was lowest for the wind pollination treatment $(35.8 \pm 4.6 \mathrm{~g})$. In summary, kiwifruit flowers were pollen limited when insects were not allowed to access them as well as after a single visit of a honeybee because the resulting fruit was lighter than under hand pollination. The relatively low fruit weight in all the treatments may be explained by the lack of irrigation in the orchard.

\section{DISCUSSION}

In the absence of bee supplementation, there was an abundant and rich community of insects visiting kiwifruit flowers that was enough to ensure fruit set and size equal to those obtained through optimal hand pollination. Ignoring that honeybees might partially proceed from feral populations, at least half of the visitors to kiwifruit flowers $(57.0 \%)$ were wild insects. A recent review on 41 crop systems highlights the importance of flowervisitor richness for increasing fruit set as well as the higher pollination efficiency of wild bees compared to honeybees (Garibaldi et al. 2013).

Visitation patterns of insects in kiwifruit flowers were driven by the time of the day and the weather conditions. All the insect groups but non-syrphid flies showed a positive relation to temperature, and as temperature increased with hours (mean temperature rose from $15.9{ }^{\circ} \mathrm{C}$ at 0900 hours to $18.3^{\circ} \mathrm{C}$ at 1300 hours), those insects also tended to increase activity as the morning progressed. Non-syrphid flies, however, were found on the flowers in the early, colder hours or at any hour when temperature was low. A similar response was reported by Vicens and Bosch (2000b) in apple trees. They argued that flies spent the night on the flowers because of the higher temperatures resulting from radiation reflection from the petals, as what happens with other white-flowered rosaceous trees (Corbet et al. 1979). As temperature rises, those flies increase activity and abandon the flowers or are expelled by other bigger pollinators that visit the flowers from early in the morning, like bumblebees and honeybees. Therefore, non-syrphid flies are expected to contribute little to kiwifruit pollination.

At a finer scale, however, some differences arose among those insects with preference for warm conditions, as shown in the response surfaces. For instance, among the two most frequent pollinators, bumblebees could work with lower temperatures and earlier in the morning. It is well known that bumblebees are adapted to fly with low temperatures and even under soft rain (Goulson 2010). The negative effect of weather on pollinator services is expected to be stronger in early spring-blooming crops, such as cherry, apple, or blueberry (Vicens and Bosch 2000b; Bosch et al. 2006; Rogers et al. 2013), than in late spring- 
blooming crops like kiwifruit because weather conditions are normally milder as spring progresses. Temperature in June (when kiwifruit blooming occurs) in our region is benign enough to allow bee activity during much of the day (temperature during the hours the insects were sampled ranged between 12.9 and $22.3{ }^{\circ} \mathrm{C}$ ). Rainfall, however, may be more constraining as it limits the activity of most insects and may also be more year dependent. In any case, the high abundance of bumblebees might warrant the pollination service to kiwifruit even in bad weather conditions.

Therefore, fine-scale visitation patterns of kiwifruit pollinators can be considered complementary (Blüthgen and Klein 2011). Functional complementarity among species that differ in their response to weather conditions (Vicens and Bosch 2000b; Brittain et al. 2013) or in the time of the day they are active (Rader et al. 2013a) can explain the more efficient pollination service of species-rich communities of pollinators. Moreover, these richer communities could be more resilient against perturbations such as climate change (Bartomeus et al. 2013; Rader et al. 2013b).

The presence of a species-rich community visiting kiwifruit flowers may also act as a buffer against competition from other pollen and nectar sources, as pollinators differ in their floral preference (Miñarro and Prida 2013; Rosa García and Miñarro 2014). Kiwifruit flowers are relatively unattractive to insects because they produce no nectar (Hopping 1990) and thus pollinator competition may be severe when nectar-producer flowers are available (Clinch 1984; Pomeroy and Fisher 2002). Pomeroy and Fisher (2002) observed that the fidelity to kiwifruit in honeybees and $B$. terrestris was influenced by the composition of the surrounding flora: honeybees abandoned kiwifruit flowers where white clover (Trifolium repens) was abundant whereas bumblebees decreased visits to kiwifruit in the presence of abundant flowering lupin (Lupinus arboreum).

Our results corroborate earlier findings that wind pollination is insufficient to guarantee a successful fruit set and a commercial fruit size in kiwifruit and that an active transport of pollen grains by insects is needed (Donovan and Read 1990; Costa et al. 1993; Vaissiere et al. 1996; González et al. 1998; Howpage et al. 2001;
Pomeroy and Fisher 2002). Contrary to observations in apple (Thomson and Goodell 2001), pumpkin (Artz and Nault 2011), or cranberry crops (MacKenzie 1994), honeybees were faster foragers on kiwifruit flowers than bumblebees. However, bumblebees contacted stigmas more frequently than honeybees, increasing the chance of fruit set, although in the single-visit experiment they both showed a similar efficiency on fruit set, probably because in the latter fruit set was assessed after removing bags on non-visited flowers fully loaded with pollen. Although we did not time these visits, it seemed that bees spent more time on these flowers, thus increasing the probability of stigma contact and fertilization. In terms of fruit quality, bumblebees, producing a $34 \%$ heavier fruit, were also more efficient than honeybees. Insufficient fruit weight after a single honeybee visit has been previously reported (Donovan and Read 1990; Costa et al. 1993). The larger size of bumblebees may imply carrying more pollen grains, contacting more stigmas, and therefore fertilizing a higher number of ovules. In apple, bumblebees deposited more pollen on stigmas than honeybees in single visits, although no differences were found on almond (Thomson and Goodell 2001).

The contribution of a particular species to pollination should be assessed with complementary multiple criteria considering abundance, response to weather, visitation rate, and/or foraging behavior (Vicens and Bosch 2000a, b; Rogers et al. 2013). Accordingly, honeybees were numerically more important and visited more flowers per time than bumblebees although Bombus was a superior pollinator per visit, as previously observed in kiwifruit (Pomeroy and Fisher 2002). Hoverflies had a lower contribution because they were less abundant and fed or rested on the flowers, mostly without contacting stigmas, as also reported by Testolin et al. (1991) for kiwifruit flowers. Other taxa are expected to contribute less to kiwifruit pollination because of their low numbers (wild bees, ants, butterflies, beetles) or passive behavior (most non-syrphid flies used the flowers just to rest). Regarding the weather effect, all the taxa but non-syrphid flies displayed a similar response, increasing visits in warmer conditions. However, the complementary foraging patterns observed at 
fine scale may improve and stabilize pollination services. Rich pollinator communities should be promoted because species complementarity may increase pollination services in agroecosystems (Bartomeus et al. 2013; Brittain et al. 2013; Garibaldi et al. 2013; Rader et al. 2013a, b). In this study, we provide the first example of the important contribution of wild insects to the successful pollination of kiwifruit.

\section{ACKNOWLEDGMENTS}

We thank Jordi Bosch and Shelley Rogers for their helpful comments on an earlier draft. MM was supported through the DOC-INIA Program.

Services de pollinisation rendus par les insectes sauvages aux cultures de kiwi (Actinidia deliciosa)

Schémas d'activité/ comportement d'approvisionnement / efficacité pollinisatrice / complémentarité des pollinisateurs / effet du climat Bestäubung von Kiwi (Actinidia deliciosa) durch
Wildinsekten

Aktivitätsmuster / Sammelverhalten Bestäubungseffizienz / ergänzende Bestäuber Wettereffekt

\section{REFERENCES}

Artz, D.R., Nault, B.A. (2011) Performance of Apis mellifera, Bombus impatiens, and Peponapis pruinosa (Hymenoptera: Apidae) as pollinators of pumpkin. J. Econ. Entomol. 104, 1153-1161

Ashman, T.L., Knight, T.M., Steets, J.A., Amarasekare, P., Burd, M., et al. (2004) Pollen limitation of plant reproduction: ecological and evolutionary causes and consequences. Ecology 85, 2408-2421

Bartomeus, I., Park, M.G., Gibbs, J., Danforth, B.N., Lakso, A.N., Winfree, R. (2013) Biodiversity ensures plant-pollinator phenological synchrony against climate change. Ecol. Lett. 16, 1331-1338

Blüthgen, N., Klein, A.M. (2011) Functional complementarity and specialisation: The role of biodiversity in plantpollinator interactions. Basic Appl. Ecol. 12, 282-291

Bosch, J., Kemp, W.P., Trostle, G.E. (2006) Bee population returns and cherry yields in an orchard pollinated with Osmia lignaria (Hymenoptera: Megachilidae). J. Econ. Entomol. 99, 408-413
Brittain, C., Kremen, C., Klein, A.M. (2013) Biodiversity buffers pollination from changes in environmental conditions. Glob. Change Biol. 19, 540-547

Clinch, P.G. (1984) Kiwifruit pollination by honey bees 1. Tauranga observations, 1978-81. New Zeal. J. Exp. Agr. 12, 29-38

Corbet, S.A., Unwin, D.M., Prys-Jones, O.E. (1979) Humidity, nectar and insect visits to flowers, with special reference to Crataegus, Tilia and Echium. Ecol. Entomol. 4, 9-22

Costa, G., Testolin, R., Vizzotto, G. (1993) Kiwifruit pollination: an unbiased estimate of wind and bee contribution. New Zeal. J. Crop Hortic. Sci. 21, 189-195

Donovan, B.J., Read, P.E.C. (1990) Efficacy of honey bees as pollinators of kiwifruit. Acta Horticulturae 288, 220-224

Fürst, M.A., McMahon, D.P., Osborne, J.L., Paxton, R.J., Brown, M.J.F. (2014) Disease associations between honeybees and bumblebees as a threat to wild pollinators. Nature 506, 364-366

Garibaldi, L.A., Steffan-Dewenter, I., Winfree, R., Aizen, M.A., Bommarco, R., et al. (2013) Wild pollinators enhance fruit set of crops regardless of honey bee abundance. Science 339, 1608-1611

González, M.V., Coque, M., Herrero, M. (1998) Influence of pollination systems on fruit set and fruit quality in kiwifruit (Actinidia deliciosa). Ann. Appl. Biol. 132, 349-355

Goulson, D. (2010) Bumblebees: behaviour, ecology, and conservation, 2nd edn. Oxford University Press, London

Graystock, P., Yates, K., Evison, S.E., Darvill, B., Goulson, D., Hughes, W.O. (2013) The Trojan hives: pollinator pathogens, imported and distributed in bumblebee colonies. J. Appl. Ecol. 50 , 1207-1215

Holzschuh, A., Dudenhöffer, J.H., Tscharntke, T. (2012) Landscapes with wild bee habitats enhance pollination, fruit set and yield of sweet cherry. Biol. Conserv. 153, 101-107

Hopping, M.E. (1990) Floral biology, pollination, and fruit set. In: Warrington, I.J., Weston, G.C. (eds.) Kiwifruit: science and management, pp. 71-96. Ray Richards Publisher, New Zealand

Howpage, D., Spooner-Hart, R.N., Vithanage, V. (2001) Influence of honeybee (Apis mellifera) on kiwifruit pollination and fruit quality under Australian conditions. New Zeal. J. Crop. Hort. 29, 51-59

Ings, T.C., Ward, N.L., Chittka, L. (2006) Can commercially imported bumblebees out-compete their native conspecifics? J. Appl. Ecol. 43, 940-948

Klein, A.M., Vaissière, B.E., Cane, J.H., Steffan-Dewenter, I., Cunningham, S.A., Kremen, C., Tscharntke, T. (2007) Importance of pollinators in changing landscapes for world crops. Proc. R. Soc. B 274 , 303-313

Mackenzie, K.E. (1994) The foraging behaviour of honeybees (Apis mellifera $\mathrm{L}$ ) and bumblebees (Bombus spp) on cranberry (Vaccinium macrocarpon Ait). Apidologie 25, 375-383 
Monceau, K., Bonnard, O., Thiéry, D. (2014) Vespa velutina: a new invasive predator of honeybees in Europe. J. Pest Sci. 87, 1-16

Miñarro, M., Prida, E. (2013) Hedgerows surrounding organic apple orchards in northwest Spain: potential to conserve beneficial insects. Agric. Forest Entomol. 15, 382-390

Pomeroy, N., Fisher, R.M. (2002) Pollination of kiwifruit (Actinidia deliciosa) by bumblebees (Bombus terrestris): effects of bee density and patterns of flower visitation. New Zeal. Entomol. 25, 41-49

Rader, R., Edwards, W., Westcott, D.A., Cunningham, S.A., Howlett, B.G. (2013a) Diurnal effectiveness of pollination by bees and flies in agricultural Brassica rapa: Implications for ecosystem resilience. Basic Appl. Ecol. 14, 20-27

Rader, R., Reilly, J., Bartomeus, I., Winfree, R. (2013b) Native bees buffer the negative impact of climate warming on honeybee pollination of watermelon crops. Glob. Change Biol. 19, 3103-3110

Read, P.E.C., Donovan, B.J., Griffin, R.P. (1989) Use of bumblebees, Bombus terrestris, as pollinators of kiwifruit and lucerne in New Zealand. New Zeal. Entomol. 12, 19-23

Rogers, S.R., Tarpy, D.R., Burrack, H.J. (2013) Multiple criteria for evaluating pollinator performance in highbush blueberry (Ericales: Ericaceae) agroecosystems. Environ. Entomol. 42, 1201-1209
Rosa García, R., Miñarro, M. (2014) Role of floral resources in the conservation of pollinators in cider apple orchards. Agr. Ecosyst. Environ. 183, 118-126

Sharma, M., Mattu, V.K., Thakur, M.L. (2013) Pollination studies on kiwi crop (actinidioa deliciosa Chev.) in Himachal Pradesh, India. Int. J. Adv. Biol. Res. 3, 545-548

Testolin, R., Vizzotio, G., Costa, G. (1991) Kiwifruit pollination by wind and insects in Italy. New Zeal. J. Crop Hort. 19, 381-384

Thomson, J.D., Goodell, K. (2001) Pollen removal and deposition by honeybee and bumblebee visitors to apple and almond flowers. J. Appl. Ecol. 38, 1032-1044

Vaissiere, B.E., Rodet, G., Cousin, M., Botella, L., Torre Grossa, J.P. (1996) Pollination effectiveness of honeybees (Hymenoptera: Apidae) in a kiwi fruit orchard. J. Econ. Entomol. 89, 453-461

vanEngelsdorp, D., Evans, J.D., Saegerman, C., Mullin, C., Haubruge, E., et al. (2009) Colony Collapse Disorder: A Descriptive Study. PLoS One 4 (8), e6481

Vicens, N., Bosch, J. (2000a) Pollinating efficacy of Osmia cornuta and Apis mellifera (Hymenoptera: Megachilidae, Apidae) on 'Red Delicious' apple. Environ. Entomol. 29, 235-240

Vicens, N., Bosch, J. (2000b) Weather-dependent pollinator activity in an apple orchard, with special reference to Osmia cornuta and Apis mellifera (Hymenoptera: Megachilidae and Apidae). Environ. Entomol. 29, 413-420 